\title{
Function of myosin during entry and egress of equid herpesvirus type 1 in primary murine neurons
}

\author{
J. CYMERYS ${ }^{1}$, A. SŁOŃSKA ${ }^{1,2^{*}}$, J. SKWARSKA ${ }^{3}$, M. W. BAŃBURA ${ }^{1}$
}

\begin{abstract}
${ }^{1}$ Division of Microbiology, Department of Preclinical Sciences, Faculty of Veterinary Medicine, Warsaw University of Life Sciences - SGGW, Ciszewskiego 8, 02-786, Warsaw, Poland; ${ }^{2}$ Division of Physiology, Department of Physiological Sciences, Faculty of Veterinary Medicine, Warsaw University of Life Sciences-SGGW, Nowoursynowska 159, 02-776 Warsaw, Poland; ${ }^{3}$ Faculty of

Horticulture, Biotechnology and Landscape Architecture, Warsaw University of Life Sciences-SGGW, Warsaw, Poland
\end{abstract}

Received December 9, 2015; revised April 26, 2016; accepted October 17, 2016

\begin{abstract}
Summary. - Equid herpesvirus type 1 (EHV-1) is a major pathogen of horses with a worldwide distribution, which can cause various clinical signs ranging from mild respiratory disease to neurological disorders. To initiate an effective infection, EHV-1 evolved a broad spectrum of mechanisms exploiting the host cell, including its actin filaments. An actin-myosin-driven transport has been described to precede cellular entry of different viruses. Therefore, in the present study we investigated the role of actin motor protein - myosin, during replication of two EHV-1 strains: Jan-E (wild-type EHV-1 strain isolated from aborted equine fetus) and Rac-H (attenuated strain highly adapted in cell cultures in vitro) in primary murine neurons. In order to investigate this, we used two inhibitors: blebbistatin (BLB; non-muscle myosin II inhibitor) and 2,3-butanedione monoxime (BDM; inhibitor of myosin ATPase). Our results demonstrated that limitation of Jan-E EHV-1 replication occurred in cells treated with myosin inhibitor, which confirmed the important role of actin motor proteins during the entry and egress of EHV-1 virions. Application of blebbistatin did not affect Rac-H EHV-1 replication, while $\mathrm{BDM}$ caused reduction of replication in murine neurons. Based on these results it can be assumed that EHV-1 virion movement was myosin-dependent.
\end{abstract}

Keywords: equid herpesvirus 1 (EHV-1); primary murine neurons; myosin; blebbistatin (BLB); 2,3butanedione monoxime (BDM)

\section{Introduction}

As intracellular parasites, viruses have developed many mechanisms to facilitate their replication in the host cell. One possible mechanism of viral influence upon the cell is affecting the cytoskeleton and its components, including motor proteins. Transformations in the actin cytoskeleton organization occur at several points in the replication cycle of the viruses, including internalization, intracellular movement and intercellular spread. Due to the type of interactions

*Corresponding author. E-mail: anex007@op.pl; phone: +48225936055.

Abbreviations: $\mathrm{BLB}=$ blebbistatin; $\mathrm{BDM}=2,3$-butanedione monoxime; EHV-1 = equid herpesvirus 1; HSV-1 = herpes simplex virus $1 ;$ p.i. $=$ post inoculation between virus and actin cytoskeleton, viruses can cause rearrangement, depolymerization or even destruction of actin cytoskeleton, since it may constitute a barrier during cell penetration or prevent the escape of progeny virions from the cell. On the other hand, virions can stimulate actin polymerization and form various kinds of actin-containing profusions to facilitate transmission of particles between the adjacent cells (Słońska et al., 2012). In our previous studies we showed that during EHV-1 infection of primary murine neurons, both types of interactions between virus and actin cytoskeleton occurred. Jan-E EHV-1 (field strain) has caused formation of actin-containing projections that established intimate contact with adjacent cells and served to propel newly produced virions from cell to cell, whereas Rac-H EHV-1 (reference strain) induced the destruction of actin filaments, apparently to affect efficient egress (Słońska 
et al., 2014). As reported in literature, a number of viruses overcome a dense network of cortical actin presumably by myosin. It was shown that during herpes simplex 1 (HSV-1) infection, myosin facilitated transport of progeny virions and it was involved in HSV-1 egress (Lyman and Enquist, 2009; Roberts and Baines, 2011). VP22, the major tegument protein of HSV-1, interacted with the actin-associated motor protein non-muscle myosin IIA (NMIIA) and both proteins colocalized within virus-induced projections emanating from the cell surface of infected Vero cells (van Leeuven et al., 2002). Moreover, the use of the BDM during HSV-1 infection resulted in an increased number of viral particles in the vicinity of the cell nucleus and reduction in the release of progeny virions (Bearer and Satpute-Krishnan, 2002).

According to the results obtained in our previous research, we have decided to define the role of microfilament associated motor protein-myosin during EHV-1 infection in primary murine neurons. In current study we have used two myosin inhibitors-BLB; non-muscle myosin II inhibitor) and 2,3-butanedione monoxime (BDM; inhibitor of myosin ATPase) at two different time points - prior to infection and $18 \mathrm{hrs}$ p.i. in order to verify the role of myosin both during the entry and egress of the progeny virions.

\section{Materials and Methods}

Virus. In this study two neurotropic strains of EHV-1 from the virus collection of the Virology Laboratory of the Department of Preclinical Sciences WULS-SGGW were used. Jan-E is a field strain isolated from aborted fetus (mare Ezelda, Janow Podlaski stud, Poland; $12^{\text {th }}$ passage in ED cells) and identified by PCR using gB-specific primers (Borchers and Slater, 1993). Rac-H is a reference strain isolated from mare Heraldia, Racot stud, Poland, which has been passaged through a series of cell cultures, and described as 'pantropic', non-pathogenic.

Cells. Balb/c (H-2 $)$ mice genetically susceptible to EHV-1 infection were used to establish primary culture of murine neurons, as described before (Cymerys et al., 2010). Primary murine neurons were cultured in B-27 Neuron plating medium, consisting of neurobasal medium, B-27 supplement, $200 \mathrm{mmol} / \mathrm{l}$ of glutamine, $10 \mathrm{mmol} / \mathrm{l}$ of glutamate and penicillin/streptomycin antibiotics with $10 \%$ supplement of fetal bovine (5\%) and equine serum (5\%) (Gibco Life Technologies). Cells were plated onto poly-D-lysine with laminin - coated sterile coverslips at a density of $5 \times 10^{4}$ neurons per well $\left(3.6 \mathrm{~cm}^{2}\right)$ and maintained at $37^{\circ} \mathrm{C}$ in $5 \% \mathrm{CO}_{2}$. Next, primary murine neuron cultures $\left(10^{5}\right.$ cells per well $\left./ 3.6 \mathrm{~cm}^{2}\right)$ were infected with either Jan-E or Rac-H EHV-1 (MOI 1.0). After onehour incubation with EHV-1, the inoculum was removed and fresh culture medium was added. Subsequently, cells were incubated for $24 \mathrm{hr}$ at $37^{\circ} \mathrm{C}$ with $5 \% \mathrm{CO}_{2}$.

Inhibitor treatment. Blebbistatin (BLB, non-muscle myosin II inhibitor; Sigma Aldrich) and 2,3-butanedione monoxime (BDM, inhibitor of myosin ATPase; Sigma Aldrich) were used to inhibit actin motor protein-myosin. BLB and BDM were dissolved in dimethylsulfoxide (5\% DMSO) to obtain final concentrations: $1 \mu \mathrm{l} / \mathrm{ml}, 2.5 \mu \mathrm{l} / \mathrm{ml}$ and $5 \mu \mathrm{l} / \mathrm{ml}$ for BLB and $10 \mu \mathrm{l} / \mathrm{ml}, 20 \mu \mathrm{l} / \mathrm{ml}$ and $30 \mu \mathrm{l} / \mathrm{ml}$ for BDM. Inhibitors were added to the culture medium at two different time points: (i) $30 \mathrm{~min}$ before infection and (ii) at 18 hr p.i. Neither inhibitor was toxic to the neurons at the concentrations used as measured by MTT cell viability assay, following the manufacturer's protocol (data not shown, Sigma Aldrich). At 24 hr p.i. viral DNA was isolated from appropriate material (cells or culture medium) using High Pure Viral Nucleic Acid Kit (Roche Diagnostics) according to manufacturer's instructions and analyzed using real-time PCR technique.

Real-time PCR. The quantity of EHV-1 DNA in all samples was estimated using real-time PCR technique with fluorescent TaqMan probe (TaqMan Master Kit; Roche Diagnostics), complementary to the sequence within the amplified product. Jan-E EHV-1 strain serial dilutions from $\mathrm{CCID}_{50}=10^{6}\left(10^{6}\right.$ copies $\left./ \mathrm{ml}\right)$ to $\mathrm{CCID}_{50}=10^{2}\left(10^{2}\right.$ copies $\left./ \mathrm{ml}\right)$ were used as reaction standards. Uninfected primary murine neuronal cells were used as negative control. Each sample was amplified with internal control (positive control) that constituted infected neuronal cells incubated without inhibitors. Tests were performed on the LightCycler 2.0 instrument (Roche Diagnostics) according to the in-house quantitative method (Dzieciątkowski et al., 2009).

Immunofluorescent staining procedures. In order to demonstrate the effect of myosin inhibitors on the actin filaments and effect of EHV-1 infection in neurons immunofluorescence staining was performed. After incubation with the virus and application of inhibitors (as described earlier), cells were fixed with 3.7\% paraformaldehyde/PBS (Sigma Aldrich) and permeabilized with $0.5 \%$ Triton X-100/PBS (Sigma Aldrich). Afterwards, fixed neuronal cells were blocked with PBS containing $1 \%$ bovine serum albumin (BSA) (Sigma Aldrich). Filament structures of actin were visualized using TRITC phalloidin conjugate (500 ng/ml; Sigma Chemicals). The presence of viral antigen was detected using polyclonal antiserum EHV-1/ERV conjugated to FITC (VMRD, Inc.). Cell nuclei were stained with Hoechst 33258 according to the manufacturer's recommendations. Then, anti-fade mounting medium (Sigma Aldrich) was applied. Results were evaluated using a confocal laser scanning microscope FV10i (Olympus Polska Sp. z o.o.).

Statistical analysis. Results of three independent experiments were statistically evaluated by one-way analysis of variation (ANOVA) using the Student-Newman-Keuls multiple comparisons test. This analysis was performed using GraphPad PrismTM version 4.03 software (GraphPad Software Inc., San Diego, CA, USA). Statistical differences were interpreted as significant at $p<0.05$, highly significant at $p<0.01$ and non-significant at $p>0.05$.

\section{Results and Discussion}

Myosin, in a close cooperation with actin filaments, participates in organization of the cytoskeleton, cytokinesis, cell 
migration and maintenance of polarity (Reichl et al., 2008; Muller et al., 2013). In neurons, myosin is responsible for axonal transportation for short distances, but it also plays an important role in the formation and stabilization of adherens and tight junctions (Liu and Cheney, 2012). Therefore, we have determined the effects of myosin inhibitors-BLB (nonmuscle myosin II inhibitor) and 2,3-butanedione monoxime (BDM; inhibitor of myosin ATPase) on actin cytoskeleton structure in murine neurons cultured in vitro (Fig. 1). Addition of BDM (Fig. 1b) or BLB (Fig. 1c) led to disorganization of the actin cytoskeleton, even though cell morphology

(b)
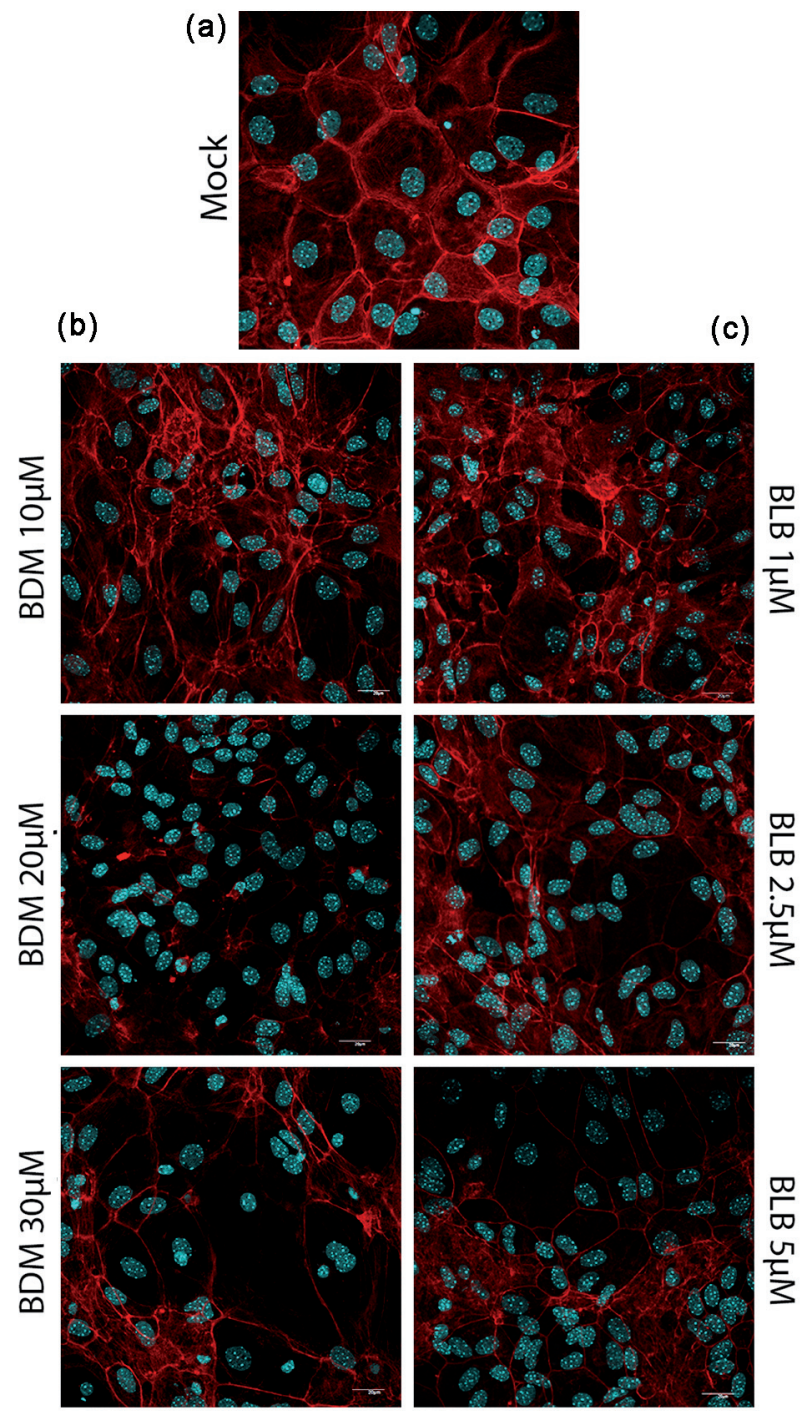

Fig. 1

The effect of myosin inhibitors on the structure of the actin cytoskeleton in primary murine neurons

Fluorescence images of mock-treated (a), BDM-treated (b) or BLB-treated (c) cells. Actin filaments are shown in red and DNA in blue. Scale bars $25 \mu \mathrm{m}$. was generally not disrupted. With increasing concentration of both inhibitors, visible disappearance of microfilament network inside the cells was observed, whereas filaments in the cortical cytoplasm remained unchanged. In order to determine the role of myosin during penetration and replication of EHV-1 in neurons, BDM or BLB was added 30 minutes before infection. Since EHV-1 replication cycle is estimated to be $24 \mathrm{hrs}$, inhibitors were also added at 18 hrs post inoculation (p.i.) to determine the role of myosin during egress of progeny virions from the cell.

Infection with Jan-E EHV-1 did not disrupt the structure of actin cytoskeleton. Accumulation of viral antigen was observed around the nucleus, as well as inside actin-containing projections that stretched from cell to cell (Fig. 2a, arrows). Despite addition of BDM, the presence of viral antigens was detected around the nucleus (Fig. 2b, arrows), but also at the cell periphery. BDM affected the actin cytoskeleton used by Jan-E EHV-1 at late stages of infection during viral egress. Following the application of BDM, virus was not able to form any kind of actin-containing projections and progeny virions were "trapped" in the cortical layer of the cytoplasm (Fig. 2b, arrowheads). The viral genome copy number decreased after adding this inhibitor, which was confirmed by realtime PCR. A significant ( $p<0.01$ and $p<0.05$, respectively) decrease of the viral DNA, both in cells and culture medium was observed, regardless of the timing of BDM addition (Fig. 4a,b). Similar results were obtained after adding BLB to the neuronal cultures infected with Jan-E EHV-1. Addition of BLB caused accumulation of EHV-1 antigens inside perikaryons of neurons (Fig. 2c, arrows). The presence of viral antigen in the cortical cytoplasm of neurons at $24 \mathrm{hr}$ p.i. suggests that progeny virons were captured within the cell and intercellular spread was inhibited, as indicated by the decrease in the amount of viral DNA (both in cells and culture medium) measured by real-time PCR (Fig. 4c,d). These results confirm that EHV-1 Jan-E strain can use microfilaments with motor protein-myosin, during the initial and final stages of infection. This was evidenced by the greater amount of viral particles immobilized within cells after addition of inhibitors at $18 \mathrm{hr}$ p.i. and by limitation of Jan-E EHV-1 replication in neurons treated with inhibitors $30 \mathrm{~min}$ prior to infection. Analysis of the level of viral DNA in Jan-E EHV-1-infected neurons also revealed that administration of BDM and BLB inhibitors to the culture $30 \mathrm{~min}$ prior to infection effectively reduced viral genome copy number in comparison to administration of these inhibitors at 18 hr p.i. Similar results were observed during African swine fever virus (ASFV) infection. BLB caused inhibition of viral replication, particularly significant if the inhibitor was added before infection, which suggests an important role of myosin II in the early stages of viral infection 
(b)
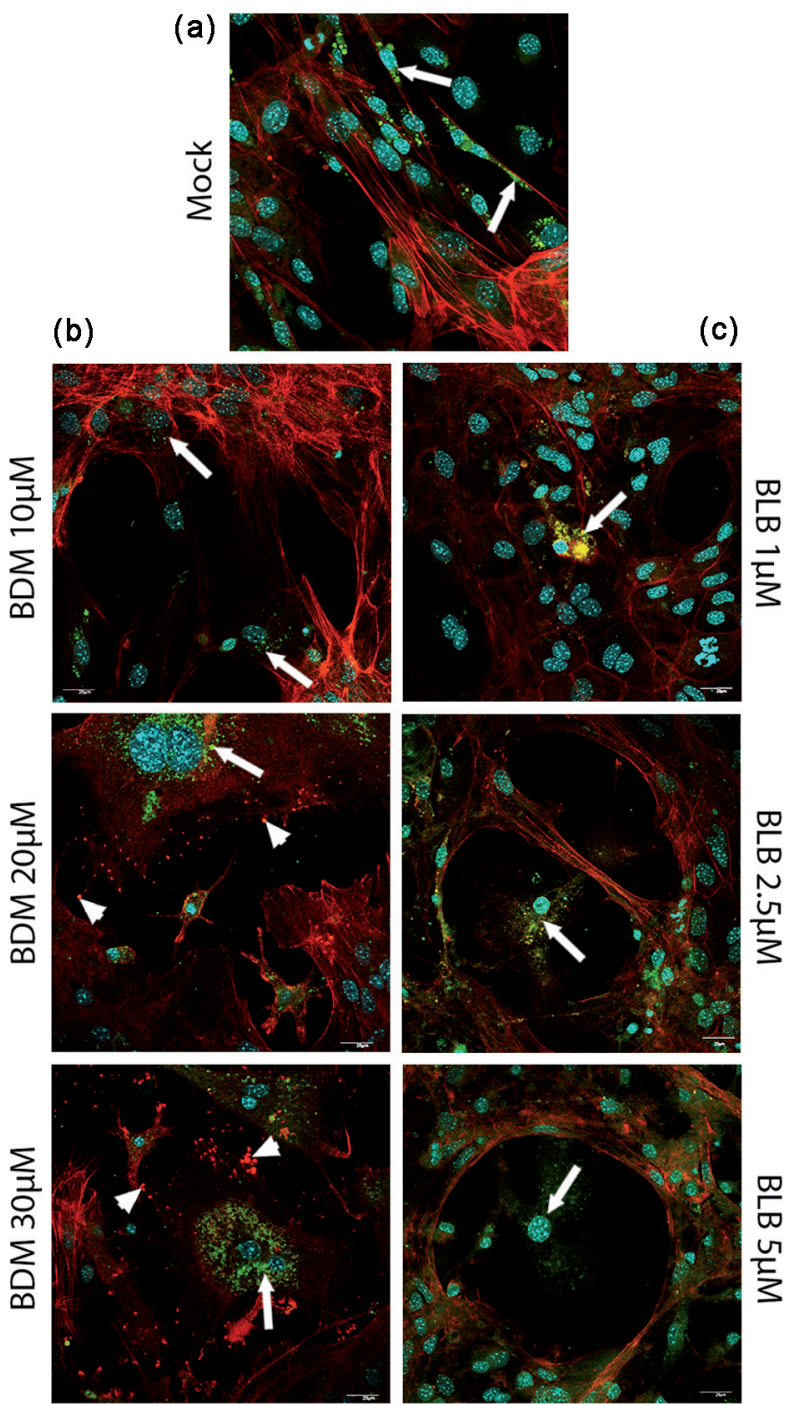

Fig. 2

The effect of myosin inhibitors on Jan-E EHV-1 localization in primary murine neurons

Fluorescence images of mock-treated (a), BDM-treated (b) or BLB-treated (c) cells infected with Jan-E EHV-1 (24 hr p.i.). Actin filaments are shown in red, EHV-1 antigens in green and DNA in blue. Arrows indicate viral antigen around the nucleus, as well as inside actin-containing projections that stretched from cell to cell. Arrowheads show virions trapped in the cortical cytoplasm. Scale bars - $200 \mu \mathrm{m}$ (a) and $20 \mu \mathrm{m}(\mathrm{b}-\mathrm{c})$.

(Sanchez et al., 2012). The role of non-muscle myosin during intracellular transport and egress of the progeny virions was also confirmed for HSV-1 (van Leeuwen et al., 2002). The use of BDM at $12 \mathrm{hr}$ p.i. inhibited the release of progeny virions as much as 20 -fold compared to untreated control. Moreover, it is worth noting that more effective reduction in the amount of Jan-E EHV-1 DNA in neurons was achieved by inhibitor of myosin ATPase (BDM), when compared to non-muscle myosin II inhibitor (BLB). This (a)

(b)

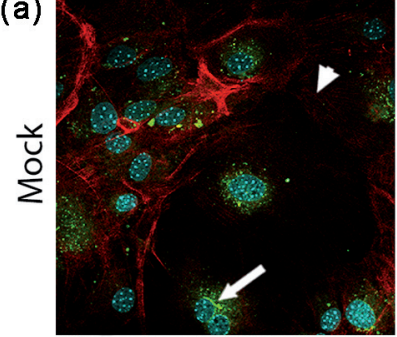

(c)
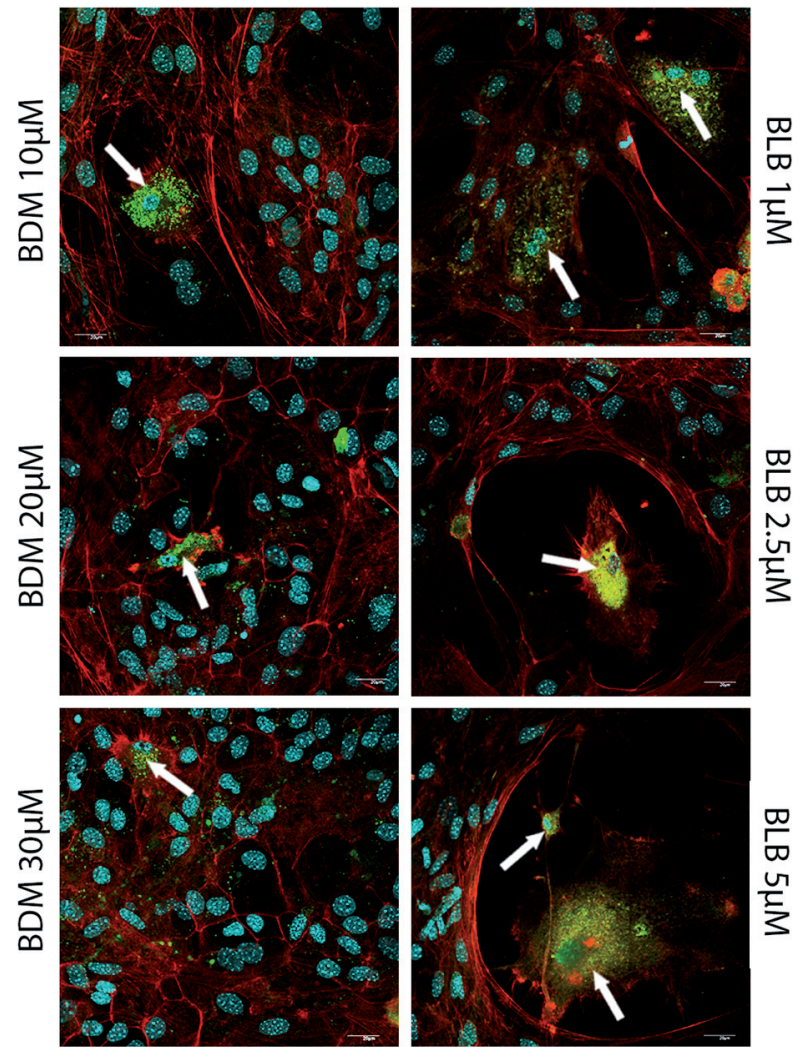

Fig. 3

The effect of myosin inhibitors on Rac-H EHV-1 localization in primary murine neurons

Fluorescence images of mock-treated (a), BDM-treated (b) or BLB-treated (c) cells infected with Rac-H EHV-1 (24 hr p.i.). Actin filaments are shown in red, EHV-1 antigens in green and DNA in blue. Arrowhead on panel A shows depolymerisation of actin filaments. Arrows indicate accumulation of viral antigens around and inside the nucleus. Scale bars $-20 \mu \mathrm{m}$.

probably results from the fact that BLB is characterized by a high affinity and selectivity for non-muscle myosin II without affecting other unconventional myosins (Kovacs et al., 2004). However, concerning BDM studies, the interactions of the inhibitor with various other elementsmyosin II, V and VI, as well as with proteins participating in the polymerization of actin fibers (complex Arp2/3, WAVE or VASP) has to be taken to account (Yarow et al., 2003; Bond et al., 2013). 
(a)

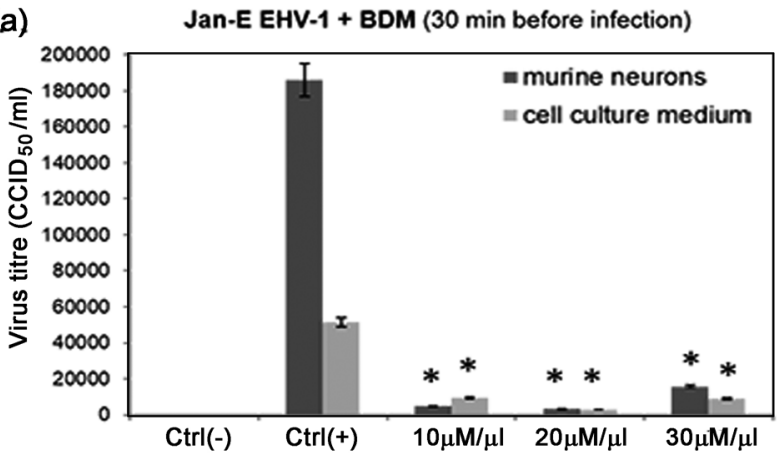

(c)

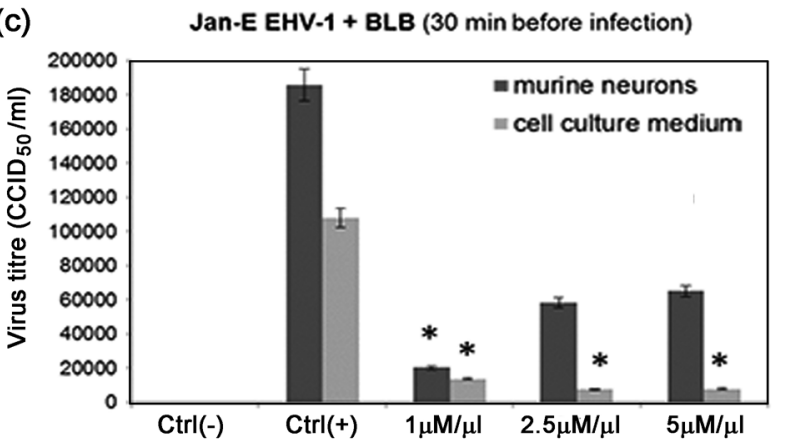

(e)

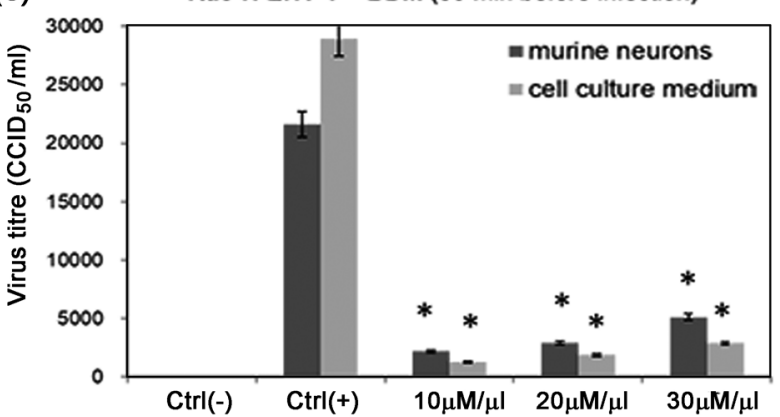

(g)

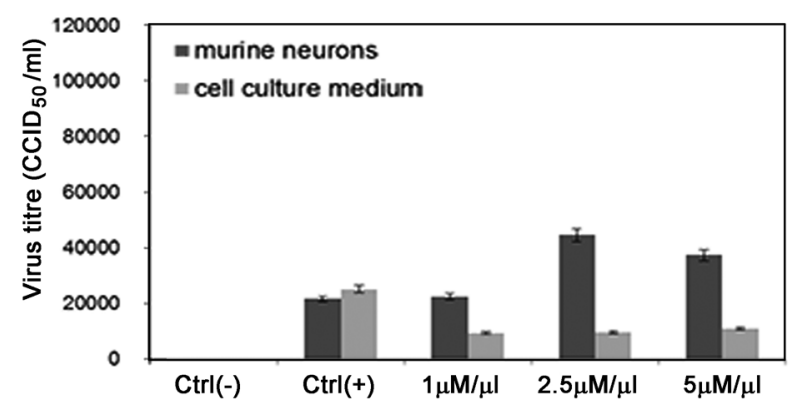

(b)

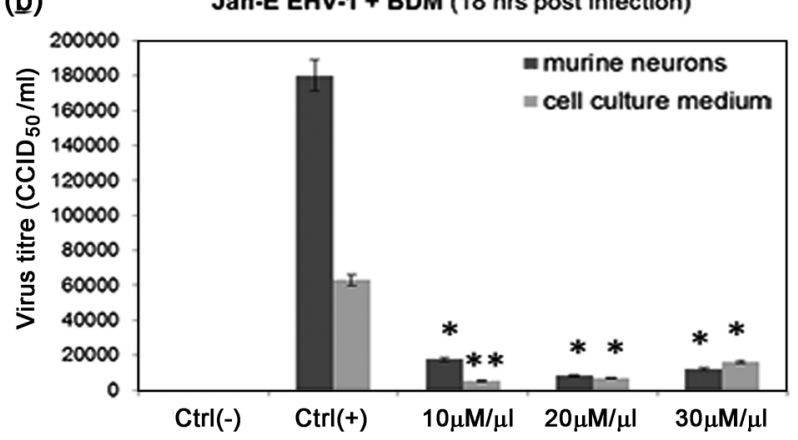

(d)
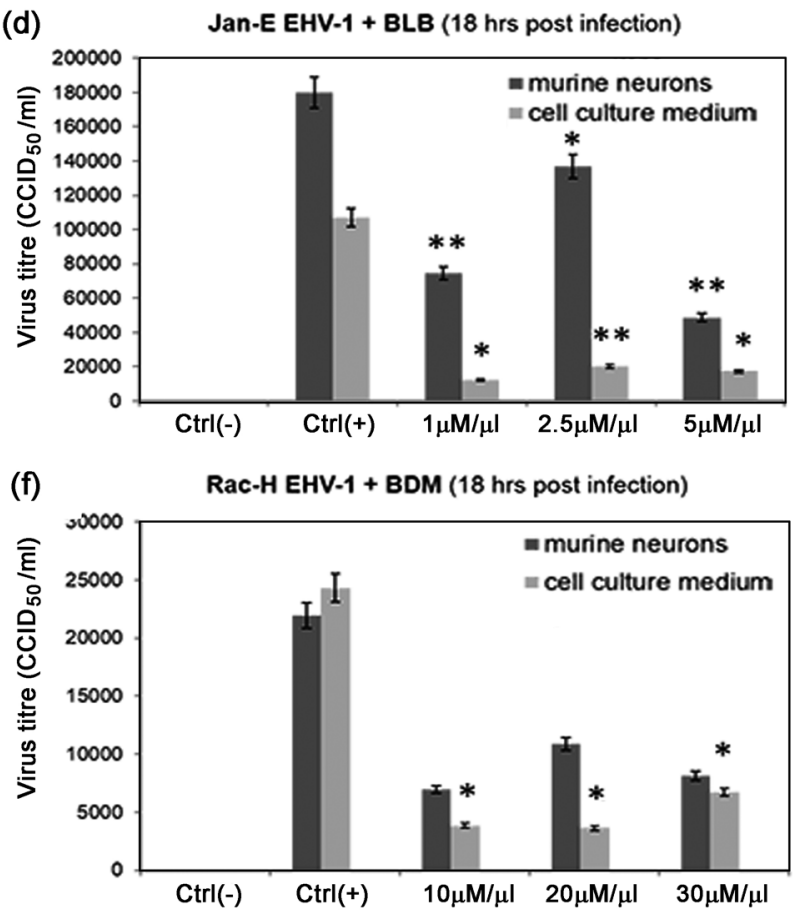

(h) Rac-H EHV-1 + BLB (18 hrs post infection)

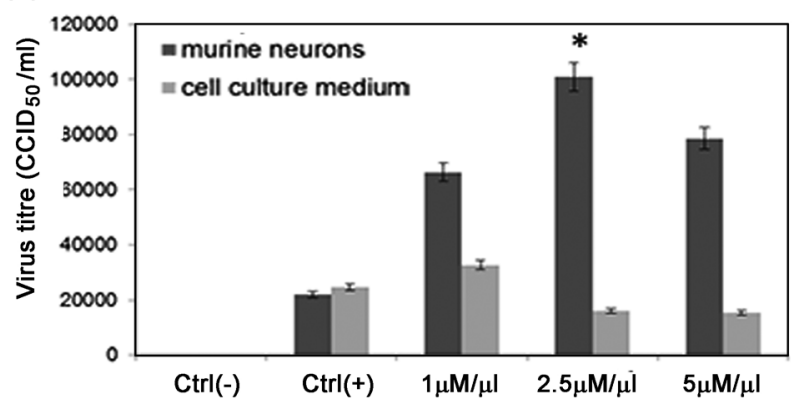

Fig. 4

Myosin inhibitors affect EHV-1 replication in primary murine neurons

Comparison of viral DNA $\left(\mathrm{CCID}_{50}\right)$ in mock-infected cells (negative control), neurons infected with Jan-E or Rac-H EHV-1 (positive control) and BDM or BLB-treated infected neurons $\left({ }^{* *} p<0.01 ;{ }^{*} p<0.05\right)$. 
Infection with the Rac-H EHV-1 disrupted the microfilament system and caused general depolymerisation of actin in murine neurons (Fig. 3a, arrowhead), accompanied by the accumulation of viral antigens around and inside the nucleus (Fig. 3a, arrow). In BDM-treated cells, in only a few cells viral antigens localized around the nucleus in comparison to mock-treated infected neurons (Fig. 3b). From this we can assume that myosin inhibitor affected virus transport to the nucleus, which significantly reduced replication, as confirmed by real-time PCR (Fig. 4e,f). A significant decrease of the viral DNA was noticed, both in cells and culture medium, regardless of the timing of BDM administration (Fig. 4a,b). Furthermore, it was observed that in the infected neurons treated with BDM, actin network was disrupted to the lesser extent than in the infected culture without an inhibitor (Fig. $3 \mathrm{~b}$ and a, respectively). It seems to be logical, because if the virus was not able to replicate, it could not induce depolymerisation of actin filaments during egress. In BLB-treated neurons, accumulation of large amounts of viral antigen in perikaryons was observed (Fig. 3c, arrows). This is consistent with the real-time PCR analysis, which showed an increase in viral DNA in the BLB-treated cells, when compared to the mock-treated cells (Fig. 4g,h). These results may indicate that Rac-H EHV-1 utilised other components of the cytoskeleton during intracellular transport. Similar findings were obtained by Frampton et al. (2010), who demonstrated that post-entry EHV-1 also utilised microtubules with dynein for movement to nucleus. It is also worth noting that due to the repeated passaging of the $\mathrm{Rac}-\mathrm{H}$ strain in various cell lines, some parts of the viral genome have been deleted, significantly reducing its virulence. The Jan-E EHV-1 has a low number of passages and lacks defects in the DNA. Consequently, we observed a non-uniform effect of tested EHV-1 strains on the cytoskeleton of the infected neurons. It seems very likely that both strains developed different strategies and mechanisms of interaction with the host cytoskeleton to facilitate efficient use of intracellular transport (Turowska et al., 2010; Słońska et al., 2014).

Acknowledgements. This work was supported by the grant No. NN308 028739 from Polish Ministry of Science and Higher Education.

\section{References}

Bearer EL, Satpute-Krishnan P (2005): The Role of the Cytoskeleton in the Life Cycle of Viruses and Intracellular Bacteria: Tracks, Motors, and Polymerization Machines. Curr. Drug Targets Infect. Disord. 2, 247-264. https:/doi. org/10.2174/1568005023342407

Bond LM, Tumbarello DA, Kendrick-Jones J, Sellers JR, Buss F (2013): Small-molecule inhibitors of myosin proteins.
Future Med. Chem. 5, 41-52. https:/doi.org/10.4155/ fmc.12.185

Borchers K, Slater J (1993): A nested PCR for the detection and differentiation of EHV-1 and EHV-4. J. Virol. Methods 45, 331-336. https:/doi.org/10.1016/0166-0934(93)90117-A

Cymerys J, Dzieciątkowski T, Słońska A, Bierła J, Tucholska A, Chmielewska A, Golke A, Bańbura MW (2010): Equine herpesvirus type 1 (EHV-1) replication in primary murine neurons culture. Pol. J. Vet. Sci. 13, 701-708. https:/doi. org/10.2478/v10181-010-0022-3

Dzieciątkowski T, Przybylski M, Cymerys J, Turowska A, Chmielewska A, Tucholska A, Bańbura MW (2009): Equine herpesvirus type 1 quantification in different types of samples by a real-time PCR. Pol. J. Vet. Sci. 12, 311-315.

Frampton AR Jr, Uchida H, von Einem J, Goins WF, Grandi P, Cohen JB, Osterrieder N, Glorioso JC (2010): Equine herpesvirus type 1 (EHV-1) utilizes microtubules, dynein, and ROCK1 to productively infect cells. Vet. Microbiol. 24, 141, 12-21. https:/doi.org/10.1016/j.vetmic.2009.07.035

Kovács M, Tóth J, Hetényi C, Málnási-Csizmadia A, Sellers JR (2004): Mechanism of Blebbistatin Inhibition of Myosin II. J. Biol. Chem. 20, 279, 35557-35563. https:/doi. org/10.1074/jbc.M405319200

Liu KC, Cheney RE (2012): Myosins in cell junctions. Bioarchitecture 2, 158-170. https:/doi.org/10.4161/bioa.21791

Sánchez EG, Quintas A, Pérez-Nú-ez D, Nogal M, Barroso S, Carrascosa AL, Revilla Y (2012): African Swine Fever Virus Uses Macropinocytosis to Enter Host Cells. PLoS Pathog. 8, 1-22, e1002754. https:/doi.org/10.1371/journal.ppat. 1002754

Lyman MG, Enquist LW (2009): Herpesvirus Interactions with the Host Cytoskeleton. J. Virol. 83, 2058-2066. https:/doi. org/10.1128/JVI.01718-08

Müller M, Diensthuber RP, Chizhov I, Claus P, Heissler SM, Preller M, Taft MH, Manstein DJ (2013): Distinct Functional Interactions between Actin Isoforms and Nonsarcomeric Myosins. PLoS One 8, 1-9, e70636. https:/doi. org/10.1371/journal.pone.0070636

Reichl EM, Ren Y, Morphew MK, Delannoy M, Effler JC, Girard KD, Divi S, Iglesias PA, Kuo SC, Robinson DN (2008): Interactions between myosin and actin cross linkers control cytokinesis contractility dynamics and mechanics. Curr. Biol. 8, 18, 471-480. https:/doi.org/10.1016/j. cub.2008.02.056

Roberts KL, Baines JD (2011): Actin in Herpesvirus Infection. Viruses 3, 336-346. https:/doi.org/10.3390/v3040336

Słońska A, Cymerys J, Godlewski MM, Dzieciątkowski T, Tucholska A, Chmielewska A, Golke A, Bańbura MW (2014): Equine herpesvirus type 1 (EHV-1)-induced rearrangements of actin filaments in productively infected primary murine neurons. Arch. Virol. 159, 1341-1349. https:/doi. org/10.1007/s00705-013-1949-3

Słońska A, Polowy R, Golke A, Cymerys J (2012): Role of cytoskeletal motor proteins in viral infection. Post. Hig. Med. Dośw. 66, 810-817. 
Turowska A, Pająk B, Godlewski MM, Dzieciątkowski T, Chmielewska A, Tucholska A, Bańbura M (2010): Opposite effects of two different strains of equine herpesvirus 1 infection on cytoskeleton composition in equine dermal ED and African green monkey kidney Vero cell lines: application of scanning cytometry and confocal-microscopy-based image analysis in a quantitative study. Arch.Virol. 155, 733-743. https:/doi.org/10.1007/s00705-010-0622-3 van Leeuwen H, Elliott G, O'Hare P (2002): Evidence of a Role for Nonmuscle Myosin II in Herpes Simplex Virus Type 1 Egress. J. Virol. 3471-3481. https:/doi.org/10.1128/ JVI.76.7.3471-3481.2002

Yarrow JC, Lechler T, Li R, Mitchison TJ (2003): Rapid de-localization of actin leading edge components with BDM Treatment. BMC Cell Biol. 4, 5. https:/doi.org/10.1186/14712121-4-5 